\title{
Editorial: Planning for a more bio-resourceful future
}

\author{
Jeff Cooper BSC, MSC, FRGS, FCIWM
}

Former President of the International Solid Waste Association, Independent

Consultant on Renewable Energy and Technical Editor, London, UK

This themed issue focuses on bioresources and the bioeconomy, of significance to everyone; from those living from the land on a subsistence basis through to the most sophisticated agro-industrial businesses. In a world where climate change and resource crises are intensifying there is a need to ensure that we plan for all aspects of our bioeconomy to be resilient enough to tackle these issues. This themed issue deals with those broader perspectives, from the consumer in the restaurant through to regional bioresource waste management plans.

Previous articles in Waste and Resource Management have mainly dealt with different aspects of food waste, such as that by Gomez et al. (2015) which addressed the issue of waste products from food processing to be utilised as raw materials for new foods and van der Werf and Gilliland's comprehensive and detailed review article examining the measurement of food losses and food waste generation in developed countries (van der Werf and Gilliland, 2017).

The United Nations' Sustainable Development Goals have placed emphasis on the reduction of food wastage throughout the supply chain by $50 \%$ by 2030 . In developing economies, the greatest wastage occurs in the earliest stages of the supply chain from the farmer to the local market. In contrast, in developed economies the greatest wastage occurs in the latter stages of the supply chain and especially with the consumer, whether purchasing intended for home consumption or away from home.

The EU's bioeconomy strategy originally signed off in 2012 has been revised as part of the circular economy package produced by the EU Commission in December 2015 and has now been published. This is to refocus the bioeconomy strategy to ensure there is a close link to join it more firmly with other aspects of the circular economy package which was passed through all its EU procedures on 4 July 2018.

Increasingly, it is being recognised that the multivariate factors associated with the wastage of food and a multitude of other bioresources throughout their production cycle needs to be addressed, such as from forestry, agriculture and the natural environment. In addition, there are many opportunities to utilise bioresources from a variety of their waste sources in order to contribute to the development of a more circular economy on local, regional and international levels.

This themed issue therefore covers all these aspects: from Ciuffa et al. (2018) on the bioresources in catering establishments in central London through to the regional economy perspective of the Curry et al. (2018) analysis of the potential resource that could be yielded from a range of feedstocks readily available in Northern Ireland. Cooper's briefing article (Cooper, 2018) reviews the current concern with the farmto-fork perspective in the UK in order to minimise waste throughout the food production chain, which is now focusing on the earlier production stages.

Pérez-Camacho and Curry (2018) analysed the full range of bioresources that are potentially available to be harvested for further utilisation for resource and/or energy recovery through a thoroughgoing assessment of those potential resources and the options available in Northern Ireland. Their focus was specifically on the potential of anaerobic treatment through biorefinery processing to deliver a range of materials with further uses within the wider economy.

The paper by Ciuffa et al. (2018) goes to the other end of the bioresource waste management chain, at least with regard to the leisure catering sector, in order to examine the potential to improve the likelihood of those establishments undertaking greater separation of food wastes by enhancing food waste storage capacity for smaller establishments through the use of vacuum-packaging. However, as with all aspects of waste management it is individual behaviour and their decision-making processes that are crucial to enable people to contribute to the reduction of food waste and its environmental consequences; whether as customers in restaurant premises or staff working in those restaurants, individuals' behaviour is critical in changing the way in which restaurants operate to reduce food waste and its environmental consequences.

Cooper's (2018) contribution covers the full spectrum of food production and the ways in which waste can be generated from 
every stage from farm to fork in the UK. Sadly, despite the progress that had been made in the period after 2008 in cutting down household food waste the amount of food waste generated in the UK has increased slightly over the last 4 years. Nevertheless, there is still work to be done to prevent food waste losses in the processing and food manufacturing sectors of the food supply chain.

The bioresource agenda is being emphasised in the EU's circular economy package. It will be essential to ensure that there are suitable support mechanisms that are available so that in future the bioeconomy can provide a range of materials and products that can be generated from a variety of biosourced materials, as demonstrated by the article by PérezCamacho and Curry (2018). In the context of the transition to the new circular economy there will be a need to provide a full range of options to improve the management of bioresources throughout the whole global economy.

\section{REFERENCES}

Ciuffa F, Cooper J, Grimes S and Smith SR (2018) Development of a vacuum-packing system for food waste from urban catering facilities. Proceedings of the Institution of Civil Engineers - Waste and Resource Management 171(4): 114-120, https://doi.org/ 10.1680/jwarm.17.00019.

Cooper J (2018) Briefing: Food waste - next steps for food processors and manufacturers. Proceedings of the Institution of Civil Engineers - Waste and Resource Management 171(4): 91-93, https://doi.org/10.1680/jwarm.18.00006.

Curry R, Pérez-Camacho MN, Brennan R et al. (2018) Quantification of anaerobic digestion feedstocks for a regional bioeconomy. Proceedings of the Institution of Civil Engineers - Waste and Resource Management 171(4): 94-103, https://doi.org/ 10.1680/jwarm.17.00014.

Gómez A, López R, Esturo A et al. (2015) From waste products to raw materials for the development of new foods. Proceedings of the Institution of Civil Engineers - Waste and Resource Management 168(2): 55-62, https://doi.org/ warm.13.00038.

Pérez-Camacho MN and Curry R (2018) Regional assessment of bioeconomy options using the anaerobic biorefinery concept. Proceedings of the Institution of Civil Engineers - Waste and Resource Management 171(4): 104-113, https://doi.org/ 10.1680/jwarm.17.00015.

van der Werf P and Gilliland JA (2017) A systematic review of food losses and food waste generation in developed countries. Proceedings of the Institution of Civil Engineers - Waste and Resource Management 170(2): 66-77, https://doi.org/ jwarm.16.00026. 